\title{
IS DEXMEDETOMIDINE BETTER THAN MIDAZOLAM FOR MONITORED ANAESTHESIA CARE DURING INGUINAL HERNIORRHAPHY? A COMPARATIVE STUDY
}

\author{
Mohanchandra Mandal1, Subhrajyoti Chattopadhyay², Subhankar Banerjee³, Teesta Bagchi', Biswanath Sarkar5, Sekhar Ranjan Basu ${ }^{6}$
}

\begin{abstract}
${ }^{1}$ Associate Professor, Department of Anaesthesiology, North Bengal Medical College. ${ }^{2}$ Assistant Professor, Department of Anaesthesiology, North Bengal Medical College.

${ }^{3}$ Post Graduate Trainee, Department of Anaesthesiology, North Bengal Medical College.

${ }^{4}$ Post Graduate Trainee, Department of Anaesthesiology, North Bengal Medical College.

5 Post Graduate Trainee, Department of Anaesthesiology, North Bengal Medical College.

${ }^{6}$ Professor, Department of Anaesthesiology, North Bengal Medical College.
\end{abstract}

\section{ABSTRACT}

\section{BACKGROUND}

Monitored Anaesthesia Care (MAC) involves administration of drugs like sedatives, hypnotics, anxiolytic and analgesics in addition to local anaesthesia, while anaesthesia care provider monitor patient's vital parameters. Anaesthesiologist should remain vigil as minimal sedation may enter into deeper level of sedation owing to individual's variable sensitivity to these drugs. Ketamine, midazolam, propofol and other agents have been tried with variable success. Recently, dexmedetomidine is being increasingly used as a sedative component of MAC with the advantage of arousable but deep sedation while maintaining haemodynamic stability. The present study was designed to evaluate the efficacy of dexmedetomidine compared to midazolam in terms of requirement of rescue analgesics and adverse events.

\section{MATERIALS AND METHODS}

A total of 54 patients aged between 18-45 years of American Society of Anesthesiologists' (ASA) physical status 1 or 2, posted for elective herniorrhaphy (Duration $<2 \mathrm{hr}$.) under local anaesthesia were recruited to receive sedation using either dexmedetomidine or midazolam. They received either Inj. Dexmedetomidine $1 \mu \mathrm{g} / \mathrm{kg}$ intravenously over 10 minutes followed by $0.5 \mu \mathrm{g} / \mathrm{kg} / \mathrm{hr}$. or Inj. Midazolam $0.06 \mathrm{mg} / \mathrm{kg}$ via intravenous route slowly followed by $0.01 \mathrm{mg} / \mathrm{kg} / \mathrm{hr}$.

\section{RESULTS}

The sedation score achieved in both the groups were comparable. The requirement of rescue analgesics was found less $(\mathrm{P}<0.002)$ in patients receiving dexmedetomidine compared to midazolam. However, the patients receiving dexmedetomidine faced more adverse events $(\mathrm{P}<0.05)$ compared to those receiving midazolam.

\section{CONCLUSION}

Dexmedetomidine can be a better alternative to midazolam as agent of monitored anaesthesia care in view of fewer requirements of rescue analgesia and acceptable adverse event profile.

\section{KEYWORDS}

Monitored Anaesthesia Care, Midazolam, Dexmedetomidine, Herniorrhaphy.

HOW TO CITE THIS ARTICLE: Mandal M, Chattopadhyay S, Banerjee S, et al. Is dexmedetomidine better than midazolam for monitored anaesthesia care during inguinal herniorrhaphy? a comparative study. J. Evolution Med. Dent. Sci. 2016;5(51): 3295-3298, DOI: $10.14260 /$ jemds/2016/763

\section{INTRODUCTION}

Monitored Anaesthesia Care (MAC) involves administering a combination of drugs such as sedatives, hypnotics, anxiolytic and analgesics which are commonly used for the induction and maintenance of general anaesthesia. ${ }^{1}$ The desired goal of MAC is minimal physiological perturbations, while achieving quicker recovery than general anaesthesia. ${ }^{2}$ In some patients only minimal sedation in addition to local anaesthesia (Nerve block or field anaesthesia) may suffice, but in others it may require 'deep sedation' that may enter into general anaesthesia as transition for a brief period owing to variable

Financial or Other, Competing Interest: None.

Submission 29-04-2016, Peer Review 03-06-2016,

Acceptance 09-06-2016, Published 25-06-2016.

Corresponding Author:

Dr. Subhrajyoti Chattopadhyay,

C/o. Mr. Satyajit Chakroborty,

Trinayani Apartment (2 ${ }^{\text {nd }}$ Floor), Taltala,

Arabinda Pally,

Siliguri-734006, West Bengal.

E-mail:drsubhra1972@gmail.com

DOI: $10.14260 /$ jemds/2016/763 and unpredictable sensitivity of these drugs in different patients.

Over sedation may jeopardise the safety of the patient and the skills of an anaesthesia provider are necessary to manage the effects of general anaesthesia on the patient as well as to return the patient quickly to a state of 'deep' or lesser sedation. 1,3

Herniorrhaphy involves repair and strengthening of inguinal canal by opposing fascia transversalis with the conjoined tendon and posterior wall of inguinal ligament. Various anaesthetic options are available for this minor surgical procedure like spinal anaesthesia, balanced general anaesthesia, local anaesthetic infiltration (Field block), etc. Out of these anaesthetic techniques, local anaesthesia (Field block) supplemented with intravenous sedation (Equates with MAC) offers many advantages such as lesser bleeding, better postoperative analgesia and earlier ambulation of the patient.

Commonly used medications for MAC are benzodiazepines, opioids and propofol. ${ }^{4}$ Midazolam with its quick onset and offset of action still can cause prolonged 
sedation after repeated administration owing to its relatively long half-life.3,5 Dexmedetomidine is a selective $\alpha_{2}$ receptor agonist with short elimination half-life of $2 \mathrm{hrs}$. It produces analgesia, sympatholysis and titratable sedation without major respiratory depression. It reduces opioid requirement, curtails the stress response to surgery and thereby ensures a stable haemodynamic profile of the patient. Fewer fluctuations from the desired sedation level, while maintaining easy arousability makes dexmedetomidine an attractive agent for sedation during MAC for various minor day care surgeries.

Dexmedetomidine is increasingly being used as a sedative component of MAC with the advantage of maintaining haemodynamic stability during various surgical procedures. $4,6,7$

In the present study dexmedetomidine has been compared with midazolam as sedative component of Monitored Anaesthesia Care (MAC) in patients undergoing inguinal herniorrhaphy under inguinal field block. Injection fentanyl was used as rescue analgesic in both the groups when score in Visual Analog Scale score reached $>4$. It was hypothesized that the requirement of rescue analgesic would be less in patients receiving MAC using dexmedetomidine compared with midazolam.

\section{OBJECTIVES}

The present study was designed to evaluate the efficacy of dexmedetomidine compared to midazolam for providing MAC in patients undergoing inguinal herniorrhaphy under inguinal field block. This was assessed by comparing the requirement of rescue analgesic (Primary outcome) between the two groups. Additionally, the intraoperative sedation scores and haemodynamic status (In terms of heart rate and mean blood pressure) was also compared.

\section{MATERIAL AND METHODS}

After getting Institutional Ethics Committee's approval, this comparative study was carried out in patients aged between 18-45 years of American Society of Anesthesiologists (ASA) physical status 1 or 2 , posted for elective herniorrhaphy surgeries (Duration less than 2 hrs.) under local anaesthesia with sedation using either dexmedetomidine or midazolam. The study was carried out in a tertiary care centre (Govt. Medical College) and it spanned over approximately one year (From January 2015 to November 2015).

\section{Exclusion Criteria}

1. Patients with history of any of drug allergy.

2. Haemodynamically unstable patients.

3. Patients with cardiorespiratory diseases, renal diseases, liver diseases.

4. Chronic users of sedatives and narcotics, alcoholic or drug abusers.

5. Those allergic to any medications used in the study.

\section{Sample Size Calculation}

From a previous study. ${ }^{8}$, it was evident that the percentage of patients requiring rescue analgesia was $10 \%$ in dexmedetomidine group and $35 \%$ in midazolam group. It was assumed that in the present study, the percentage of patients requiring rescue analgesia will be $5 \%$ or less in the dexmedetomidine group than the midazolam group. Setting the power of the trial at $80 \%$ and considering $95 \%$ confidence limit, the sample size was calculated 24 for each group. Expecting 10\% dropout rate, sample size in each group was considered 27. Hence, a total of 54 patients was taken for this study.

\section{Sampling Design}

Using 'sealed envelope' method, the patients were randomly assigned into two groups to receive either Inj. dexmedetomidine (Group D, $\mathrm{n}=27$ ) or Inj. midazolam (Group $M, n=27$ ) as sedative agent of MAC. Sampling design was simple random sampling.

\section{Study Tools}

a. Proforma for written informed consent.

b. Proforma for data collection.

c. Pre-anaesthetic Checkup (PAC) questionnaire.

d. Inj. dexmedetomidine and Inj. midazolam, Inj. fentanyl for rescue analgesic.

e. Inj. lignocaine $2 \%$ with adrenaline $(1: 200000)$ as local anaesthetic agent.

f. Anaesthesia work-station.

g. Emergency drugs and equipment for resuscitation purpose.

\section{Study Technique}

Patients were selected during pre-anaesthetic checkup keeping in mind the exclusion criteria. Patients and guardians were explained about the procedure, the risk and benefit associated with the procedure in their vernacular language. After focused discussion about the intended procedure and purpose of the study, informed written consent was obtained from every patient for the present study. During that time, they were assured about their right to opt out from the study at any time of the study.

The patients were subjected for fasting for a period of 8 hrs. on the night before the day of surgery. On receiving the patient in the operating room, every patient was asked to choose a sealed envelope containing computer-generated random numbers.

After random allocation of patient to two groups through using this method, the patients were positioned on operating table. All patients received a prescribed anaesthetic protocol. An 18 gauze intravenous cannula was inserted and Ringer's lactate infusion was started. Multichannel monitor [containing Non-Invasive Blood Pressure (NIBP), ECG and Pulse oximetry] was attached to the patient and baseline readings were taken. Heart rate and $\mathrm{SpO}_{2}$ of the patients were monitored continuously and NIBP were monitored continually at 5 minute interval. All observed parameters were recorded at 5 minute interval for first 15 minutes and at 15 minute interval for rest of the duration.

Then the patients received either Inj. dexmedetomidine 1 $\mu \mathrm{g} / \mathrm{kg}$ intravenously over 10 minutes followed by 0.5 $\mu \mathrm{g} / \mathrm{kg} / \mathrm{hr}$. or Inj. midazolam $0.06 \mathrm{mg} / \mathrm{kg}$ via intravenous route slowly and followed by $0.01 \mathrm{mg} / \mathrm{kg} / \mathrm{hr}$. The patients received either of these two colourless medicines through syringe pumps loaded according to the random allocation protocol by one person not otherwise involved in this study. All the drugs were prepared and given by anaesthesiologists who were not involved in subsequent data collection and data analysis. During this induction of sedation, the patients were assessed using Ramsay Sedation Scale (RSS) scores (1=agitated, restless; $2=$ co-operative, tranquil; $3=$ responds to verbal 
command while sleeping; $4=$ brisk response to glabellar tap or loud voice while sleeping; $5=$ sluggish response to glabellar tap or loud voice; $6=$ no response to glabellar tap or loud voice).

The target end point was a patient having RSS $=3$ by the end of 10 mins. If the target end point was reached before completing the loading infusion, then the infusion was stopped and noted. The maintenance infusion in both the groups was commenced immediately, once the loading infusion was stopped. Inguinal field block was given by an experienced anaesthesiologist using $20 \mathrm{~mL}$ of Inj. lignocaine $2 \%$ with Inj. Adrenaline 1:200,000. Surgery was commenced after achieving adequate sensory block. Intraoperative heart rate, mean blood pressure and oxygen saturation was recorded every 5 minute intervals till the end of surgery. Intraoperative pain intensity was evaluated using VAS.

If the pain was persistent and the VAS score was 4 or more, then rescue analgesia IV fentanyl in a dose of $1 \mu \mathrm{g} / \mathrm{kg}$ was given. The number of rescue doses of fentanyl was recorded. Adverse events like bradycardia (Less than 60 beats/min), hypotension (Drop of mean arterial blood pressure 20\% of baseline or systolic BP less than $100 \mathrm{mmHg}$ ), desaturation $\left(\mathrm{SpO}_{2}<90 \%\right)$, nausea or any other event during the procedures was noted. Bradycardia was treated with intravenous atropine $0.01 \mathrm{mg} / \mathrm{kg}$ and hypotension was addressed with fluid replacement.

\section{The Following Parameters was Observed and noted \\ a. Requirement of rescue analgesia in two groups. \\ b. Intraoperative sedation score in two groups. \\ c. Blood pressure intraoperatively. \\ d. Heart rate intraoperatively.}

\section{Data Analysis}

Collected data was entered into Microsoft Excel sheet and analysed using SPSS version 12.0 for windows. Data was presented as Mean \pm SD unless mentioned otherwise. Appropriate statistical tests were used depending upon the nature of data. Haemodynamic and respiratory data was evaluated using unpaired t-test for intergroup and paired ttest for intragroup comparison. Categorical data was analysed using Chi square test. $P$ value less than 0.05 was considered as significant.

\section{RESULTS}

Two patients in dexmedetomidine group and three patients in midazolam group changed their mind after randomization at the eleventh hour in operating room. One patient in dexmedetomidine group had faced extended duration of surgery and not qualified as per the set protocol of inclusion. Thus, altogether data of six patients, three in each group were not available for analysis. Demographic parameters and duration of surgery were comparable in both the groups (Table 1). Also, the sedation score achieved in both the groups were comparable using either of the drugs (Table 2). However, the requirement of rescue analgesia was found less in patients receiving dexmedetomidine compared to midazolam as agent of MAC (Table 3). Noteworthy observation is that the patients receiving dexmedetomidine faced more adverse events compared to those receiving midazolam for MAC (Table 4).

\begin{tabular}{|c|c|c|c|}
\hline Parameters & $\begin{array}{c}\text { Dexmedetomidine } \\
(\mathbf{n = 2 4 )}\end{array}$ & $\begin{array}{c}\text { Midazolam } \\
(\mathbf{n = 2 4 )}\end{array}$ & $\begin{array}{c}\text { P } \\
\text { value }\end{array}$ \\
\hline Age (years) & $22.16 \pm 3.9$ & $22.54 \pm 3.4$ & 0.72 \\
\hline Sex (M:F)* & $18 / 6$ & $16 / 8$ & 0.39 \\
\hline $\begin{array}{c}\text { Weight } \\
\text { (kgs) }\end{array}$ & $60.4 \pm 9.1$ & $59.6 \pm 8.8$ & 0.75 \\
\hline $\begin{array}{c}\text { Duration of } \\
\text { surgery } \\
\text { (Minutes) }\end{array}$ & $102.6 \pm 7.4$ & $101.7 \pm 8.1$ & 0.69 \\
\hline $\begin{array}{c}\text { Data expressed as mean } \pm \text { SD and tested using Independent } \\
\text { samples 't' test except marked * which is expressed as } \\
\text { number of patients and tested using Pearson Chi-Square } \\
\text { test. P <0.05 is considered significant. }\end{array}$ \\
\hline \multicolumn{3}{|c|}{ Table 1: Demographic Parameters } \\
\hline
\end{tabular}

\begin{tabular}{|c|c|c|c|}
\hline Parameter & $\begin{array}{c}\text { Dexmedetomidine } \\
(\mathbf{n = 2 4 )}\end{array}$ & $\begin{array}{c}\text { Midazolam } \\
(\mathbf{n = 2 4 )}\end{array}$ & $\begin{array}{c}\text { P } \\
\text { value }\end{array}$ \\
\hline $\begin{array}{c}\text { Ramsay } \\
\text { Sedation } \\
\text { Scale } \\
\text { Scores }\end{array}$ & $4.1 \pm 0.17$ & $4.02 \pm 0.15$ & 0.09 \\
\hline \multicolumn{3}{|c|}{$\begin{array}{c}\text { Data expressed as mean } \pm \text { SD. Test done: Independent } \\
\text { samples ' } \mathrm{t} \text { ' test }(\mathrm{P}<0.05 \text { considered significant) }\end{array}$} \\
\hline \multicolumn{3}{|c|}{ Table 2: Comparison of Sedation Score } \\
of Patients in Two Groups
\end{tabular}

\begin{tabular}{|c|c|c|c|}
\hline Parameter & $\begin{array}{c}\text { Dexmedetomidine } \\
(\mathbf{n = 2 4 )}\end{array}$ & $\begin{array}{c}\text { Midazolam } \\
(\mathbf{n = 2 4 )}\end{array}$ & $\begin{array}{c}\text { P } \\
\text { value }\end{array}$ \\
\hline $\begin{array}{c}\text { Rescue } \\
\text { Analgesia }\end{array}$ & $1 / 23(5 \%)$ & $8 / 16(33 \%)$ & 0.002 \\
\hline $\begin{array}{c}\text { Data expressed in number of patients. Test done: Pearson } \\
\text { Chi-Square test (P <0.05 considered significant) }\end{array}$ \\
\hline \multicolumn{3}{|c|}{ Table 3: Rescue Analgesia Requirement } \\
of Patients in Two Groups
\end{tabular}

\begin{tabular}{|c|c|c|c|}
\hline Parameters & $\begin{array}{c}\text { Dexmedeto- } \\
\text { midine (n=24) }\end{array}$ & $\begin{array}{c}\text { Midazolam } \\
\text { (n=24) }\end{array}$ & $\begin{array}{c}\text { P } \\
\text { value }\end{array}$ \\
\hline Hypotension & $13 / 11(54.16 \%)$ & $5 / 19(20.83 \%)$ & $<0.05$ \\
\hline Bradycardia & $10 / 14(41.67 \%)$ & $3 / 21(12.5 \%)$ & $<0.05$ \\
\hline \multicolumn{3}{|c|}{ Data expressed in number of incidence and tested using } \\
Pearson Chi-Square test (P <0.05 considered significant) \\
\hline \multicolumn{4}{|c|}{ Table 4: Adverse Events } \\
\hline
\end{tabular}

\section{DISCUSSION}

The present study finds less requirement of rescue analgesic dosage among patients receiving dexmedetomidine for their monitored anaesthesia care, although the same group suffered higher incidences of adverse events in the form of hypotension and bradycardia. In spite of these higher adverse events, the observed decrease in mean arterial pressure measurements was not to a level that could compromise haemodynamics of the patients. Patients in both groups achieved similar sedative characteristics.

Eren $\mathrm{G}$ et $\mathrm{al}^{9}$ found dexmedetomidine to be an effective agent for preoperative sedation and its administration results with equal or even longer sedation compared to high doses $(0.06 \mathrm{mg} / \mathrm{kg})$ of midazolam. Although the authors found depressive effects on haemodynamic parameters using dexmedetomidine at the dose of $1 \mu \mathrm{g} / \mathrm{kg}$, this effect did not reach the level of severe impairment. They suggested that its use just normalizes the increased levels of blood pressure and HR that arose out of preoperative anxiety. Recently, Padmaja 
A et $a l,{ }^{8}$ reported dexmedetomidine as better agent than midazolam for achieving MAC during ENT surgical procedures. Dexmedetomidine has been tested as a better agent than midazolam for MAC during cataract surgery even in the past decade.10 Dexmedetomidine has been compared with midazolam using tramadol as combination and administered via patient-controlled analgesia system during functional endoscopic sinus surgeries and there also the former drug was found to be a superior quality of sedation. ${ }^{11}$

One recent study states that the amnestic properties of dexmedetomidine are inferior to midazolam. ${ }^{12}$ Anterograde amnesia properties of midazolam may be advantageous in relieving patient's anxiety. Favourable adverse events in terms of lower incidences of bradycardia and hypotension might justify the use of midazolam over dexmedetomidine in some scenario. Again, lesser requirement of rescue analgesics and acceptable adverse events favour the use of dexmedetomidine. Preservation of hypercapnic arousal response, a feature of natural sleep, appears to be preserved during sedation with dexmedetomidine. ${ }^{13}$ Moreover, achieving deep sedation but arousable on command remains a unique advantage in dexmedetomidine sedation over midazolam.

\section{CONCLUSION}

Dexmedetomidine can be a better alternative to midazolam as agent of monitored anaesthesia care in view of fewer requirements of rescue analgesia and acceptable adverse event profile. Future study using different doses of both the two drugs are warranted to find out the optimal dose of both the drugs in this sphere of monitored anaesthesia care for comparable level of sedation.

\section{REFERENCES}

1. American Society of Anesthesiologists: Distinguishing monitored anesthesia care ("MAC") from moderate sedation/analgesia (conscious sedation). Approved by the ASA House of Delegates on October 27, 2004, last amended on October 21, 2009, and reaffirmed on October 16, 2013. Available at: www.asahq.org Accessed on 21st April, 2016.

2. Das S, Ghosh S. Monitored anaesthesia care: an overview. J Anaesthesiol Clin Pharmacol 2015;31(1):27-9.

3. Becker DE. Pharmacodynamic considerations for moderate and deep sedation. Anaesth Prog 2012;59(1):28-42.
4. Kasuya Y, Govinda R, Rauch S, et al. The correlation between bispectral index and observational sedation scale in volunteers sedated with dexmedetomidine and propofol. Anaesth Analg 2009;109(6):1811-5.

5. Bagchi D, Mandal MC, Basu SR. Arousal time from sedation during spinal anaesthesia for elective infraumbilical surgeries: comparison between propofol and midazolam. Indian J Anaesth 2014;58(4):403-9.

6. Candiotti KA, Bergese SD, Bokesch PM, et al. Monitored anaesthesia care with dexmedetomidine: a prospective, randomized, double-blind, multicenter trial. Anaesth Analg 2010;110(1):47-56.

7. Okawa K, Ischinohe T, Kaneko Y. A comparison of propofol and dexmedetomidine for intravenous sedation: a randomized, crossover study of the effects on the central and automatic nervous systems. Anaesth Analg 2010;110(2):415-8.

8. Padmaja A, Varma T, Darshini PP. A comparative study of dexmedetomidine Vs midazolam for monitored anaesthesia care during ENT surgical procedures. IOSRJDMS 2015;14:100-4.

9. Eren G, Cukurova Z, Demir G, et al. Comparison of dexmedetomidine and three different doses of midazolam in preoperative sedation. J Anaesthesiol Clin Pharmacol 2011;27(3):367-72.

10. Alhashemi JA. Dexmedetomidine vs midazolam for monitored anaesthesia care during cataract surgery. $\mathrm{Br} J$ Anaesth 2006;96(6):722-6.

11. Karaaslan K, Yilmaz F, Colak C, et al. Comparison of dexmedetomidine and midazolam for MAC combined with tramadol via patient controlled analgesia in endoscopic nasal surgery: a prospective, randomized, double-blind, clinical study. Curr Ther Res Clin Exp 2007;68(2):69-81.

12. Bavullu EN, Aksoy E, Abdullayev R, et al. Comparison of dexmedetomidine and midazolam in sedation for percutaneous drainage of hepatic hydatid cysts. Turk J Anaesth Reanim 2013;41:195-9.

13. Hillier SC, Mazurek MS. Monitored anaesthesia care. In: Barash PG, Cullen BF, Stoelting RK, et al. (editors). Clinical Anaesthesia. $6^{\text {th }}$ ed. Ch. 31, Philadelphia: Lippincott Williams and Wilkins 2009:p 828. 